\title{
A preliminary study of the effects of organic farming on oocyte quality in ewe lambs
}

\author{
A. Casao $^{1}$, G. A. María ${ }^{2}$ and J.A. Abecia ${ }^{3 *}$ \\ ${ }^{1}$ I.U.C.A. Dept de Bioquímica y Biología Molecular y Celular, Facultad de Veterinaria, \\ Zaragoza, Spain \\ ${ }^{2}$ Dept de Producción Animal y Ciencia de los Alimentos, Facultad de Veterinaria, \\ Zaragoza, Spain \\ ${ }^{3}$ I.U.C.A. Dept de Producción Animal y Ciencia de los Alimentos, Facultad de \\ Veterinaria, Zaragoza, Spain
}

* All correspondence to: José-Alfonso Abecia. IUCA. Dept de Producción Animal y Ciencia de los Alimentos, Facultad de Veterinaria, Miguel Servet, 177, 50013 Zaragoza, Spain. Tel +34876554159, Email: alf@unizar.es

Running headline: Oocyte quality in organic sheep 


\section{Abstract}

This study tested whether feeding Rasa Aragonesa ewes certified organic feed from 15 days before mating until lamb weaning, improved oocyte quality, and in vitro maturation (IVM) and fertilization (IVF) performances of the offspring. In a second experiment, ovaries from ewe lambs that were bred on an organic farm of the same breed were compared to those from conventionally bred animals. The number ( \pm S.E.M.) of healthy oocytes per ewe lamb did not differ significantly between organic (12.2 \pm 3.3 ) and

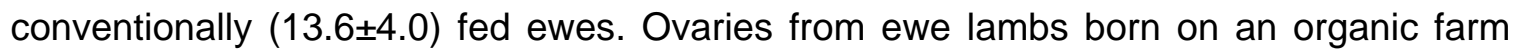
had significantly $(P<0.0001)$ more healthy oocytes per ewe lamb $(39.6 \pm 5.2)$ than did

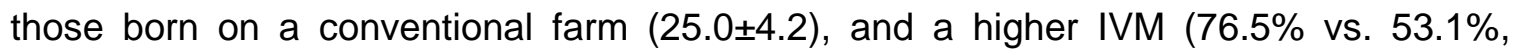
$\mathrm{P}<0.0001)$ and IVF $(97.3$ vs. $91 \%, \mathrm{P}<0.05)$. In conclusion, this preliminary approach to the study of the effect of organic procedures on the sheep oocyte quality indicates that the total integration in the complete organic system improved the oocyte quality of ewe lambs, although organic feeding alone was insufficient to improve quality.

Keywords: sheep, organic, feeding, oocyte, in vitro

\section{Introduction}

The development of fetal ovarian follicles has a significant effect on reproductive competence. The uterine environment, especially during the periconceptual period, has a significant effect on oocyte and embryo qualities (Ashworth et al., 2009), and therefore, maternal periconceptional nutrition has a significant effect on oocyte and embryo development in adulthood (Bloomfield, 2011). Exposure to endocrine-disrupting compounds (EDC) over 80-day periods during early, mid-, or late gestation reduced the proportion of healthy early-stage fetal follicles in the ovarian reserve of pregnant ewes Lea et al., 2016). Elevated EDC exposure at mating can cause significant changes in fetal ovarian histology and in the transcription of genes critical for ovarian development, which suggests that the pre-conception period is crucial for the conditioning of the longterm effects of EDC exposure on ovarian development and future fertility (Bellingham et al., 2013).

Organic farming procedures include avoiding the use of additional fertilizers, soil conditioners, and plant protection products, which might be converted into EDCs, and using livestock feed that is composed of agricultural ingredients that come from organic 
farming (European Commission, 2007), therefore, we hypothesized that organic farming might improve the oocyte quality of ewe lambs whose mothers were fed pollutant-free feed. We tested whether feeding certified organic feed from 15 days before mating until lamb weaning to ewes bred on a conventional farm improved the oocyte quality in their offspring. In a second experiment, the ovaries from ewe lambs that had been bred on a fully organic farm were compared with the ovaries from ewe lambs that had been born on a conventional farm.

\section{Materials and Methods}

\section{Experiment 1}

This study was conducted at the experimental farm of the University of Zaragoza, Spain (latitude $41^{\circ} \mathrm{N}$ ). In mid-April 2015, a flock of 30 Rasa Aragonesa ewes was synchronized in estrus by intravaginal fluorogestone acetate (FGA) sponges (Chronogest, MSD Animal Health) for 12 days, and 250 IU eCG (Folligon, MSD Animal Health) at pessary withdrawal. Rams were introduced into the flock $36 \mathrm{~h}$ later, and kept there for $48 \mathrm{~h}$.

Fifteen days before sponge insertion, ewes were fed a diet that provided the daily requirements for maintenance ( $0.5 \mathrm{~kg}$ barley, $0.5 \mathrm{~kg}$ alfalfa hay, and $1 \mathrm{~kg}$ barley straw) (AFRC, 1993). At the beginning of the hormonal treatment, ewes were allocated to one of two groups to be fed one of two diets: The Conventional (C) group $(n=15)$ received the same diet that they had been receiving and the Organic $(O)$ group $(n=15)$ received a diet that had the same feed components as did the $\mathrm{C}$ group, but they were produced on a certified-organic farm. After the fourth month of pregnancy, pregnant ewes $(n=25)$ were fed the same diets, but rations were increased to maintain their live weight plus the growth and development of the fetus (1 $\mathrm{kg}$ barley, $1 \mathrm{~kg}$ alfalfa hay, and $1 \mathrm{~kg}$ barley straw). Those diets were maintained until weaning (60 days). At that time, 12 ewe lambs that had been born a singleton and within a three-day period (six from each group of ewes) were selected and their ovaries were collected at the abattoir at 60-days old. Ewe lambs did not receive any supplemental feeding during lactation, so that they were only fed their mothers' milk.

\section{Experiment 2}

In mid-March 2016, the ovaries of six 45-day-old Rasa Aragonesa ewe lambs that had been bred on an organic-certified farm (Monegrillo, Zaragoza, Spain) were collected at the local abattoir to study their oocyte population. Animals on that farm had been bred 
following organic-farming principles and official EU laws. At the same time, six ewe lambs of the same breed born in the main flock of the experimental sheep flock of the University of Zaragoza, Spain, were sent to the abattoir and their ovaries were collected. That flock served as a "conventional" flock. Both groups of ewe lambs were fed their dams' milk until slaughter.

\section{In vitro oocyte maturation and fertilization}

Within a half-hour after slaughter, ovaries were recovered and stored at $39^{\circ} \mathrm{C}$ until they were examined. Puncture and slicing techniques were used to collect oocytes, which were classified based on their cumulus cells and cytoplasm morphology as follows (Wani et al., 1999): good (all oocytes have many complete layers of granulose cells and homogeneous cytoplasm), fair (all oocytes have few or incomplete layers of granulose cells and homogeneous cytoplasm), or poor (oocytes have few or no granulose cells and non-homogeneous cytoplasm). Good and fair (healthy) oocytes were selected for IVM. At the end of IVM, the oocytes were denuded from the cumulus cells and transferred to the fertilization medium. On the day of fertilization, the semen collected from two rams was pooled, diluted to $1: 10$ in a saline medium, and kept at $15^{\circ} \mathrm{C}$ until IVF. Highly motile spermatozoa were selected based on the Swim-up technique and added to the fertilization medium that contained the oocytes at a final concentration of $1 \times 10^{6}$ spermatozoa/ml, covered with mineral oil, and incubated for $24 \mathrm{~h}$ at $39^{\circ} \mathrm{C}$ in an atmosphere of 5\% CO2 and saturated humidity. After $48 \mathrm{~h}$, presumptive zygotes were assessed for cleavage. Non-cleaved oocytes were stained with Hoechst 33342 and examined to identify their maturation stage. After fertilization, cleaved embryos were placed in a culture medium for 8 days. Media used for oocyte collection and in vitro culture were described elsewhere (Forcada et al., 2011).

\section{Statistical analysis}

The proportions of mature and fertilized oocytes, cleaved embryos, and blastocysts were expressed as percentages for each group. Maturation and cleavage rates were calculated based on the number of healthy oocytes, fertilization rate was based on the number of mature oocytes, and blastocyst rates were based on the number of cleaved embryos or oocytes. They were evaluated statistically using Chi-square or Fisher Exact Tests, as appropriate. Total number and classification of oocytes recovered, and number of healthy oocytes selected for maturation were subjected to ANOVA. 


\section{Results and Discussion}

In experiment 1 , the oocyte quality and in vitro results did not differ significantly between the offspring of organic-feed and conventional-feed ewes (Table 1), however, in experiment 2, the number and proportion of fair oocytes in the ovaries of the ewe lambs born on the organic farm were significantly $(P<0.05)$ higher than they were in the conventionally-bred ewe lambs (Table 2). Furthermore, the population of healthy oocytes was significantly $(P<0.0001)$ higher in the ovaries of the ewe lambs born on the organic farm than it was in the ewe lambs that had been born on the conventional farm. The proportions of mature $(\mathrm{P}<0.0001)$ and fertilized $(\mathrm{P}<0.05)$ oocytes, and cleavage rate at $48 \mathrm{~h}(\mathrm{P}<0.01)$ were higher in the organic group than they were in the conventional group. However, the blastocyst/embryo rate was significantly $(P<0.05)$ higher in the conventional farm (Table 2).

To our knowledge, this is the first study to demonstrate the effects of organic farming procedures on the oocyte quality of ewe lambs, however, organic feed alone did not have a significant effect, and hence, it is likely that non-nutritional factors associated with the organic farming system affected the development of the ovaries of the ewe lambs. Organic production is an integrated agroecosystem of farm management and food production that combines best environmental practices, high animal welfare standards, and particular attention should be paid to housing conditions, husbandry practices, and stocking densities (European Commission, 2007). The organic approach seems to offer more solutions to welfare problems than do changes in farm routines or the handling of the animals (Alrøe et al., 2001), which might reduce the amount of stress experienced by the animals on organic farms, thereby, enhancing their immunological status. The acute elevation of glucocorticoids (cortisol) caused by the activation of the hypothalamic-pituitary-adrenal (HPA) axis, and immunosuppression are important aspects of the stress response in sheep (Lepherd et al., 2001). In their review of the effects of nutritional and environmental factors on the fetal programming of the reproductive axis, Rhind et al. (2001) concluded that adult reproductive performance reflects the combined effects of multiple factors as diverse as nutrition, stress and EDC exposure during prenatal development. A combination of physical and psychological stressors that cause short-term perturbations in the post-conception maternal environment had measurable effects on fetal development and gestation length (Smith et al., 2008). Although the chemical contents of the raw materials fed to the ewes in our 
experiments were not quantified, some of the ingredients in the conventional diet might have contained any substances that are not allowed in the organic feeding system. For instance, mycotoxins, which are commonly found in many food commodities, might impair the growth and reproductive efficiency of livestock and humans, e.g., mycotoxinfed mice had reduced ovarian and germinal vesicle oocyte indices (Hou et al., 2014). In addition, long-term exposure to low doses of a complex, 'real-life' cocktail of environmental chemicals, including some organochlorine pesticides that have been used extensively in agriculture in Europe, affects the developing fetal ovary of sheep (Fowler et al., 2008).

In both experiments, few mature and fertilized oocytes reached the blastocyst stage, although in experiment 2, blastocyst rate was higher in the conventional group. Potential causes of this differences remain to be elucidated, and both intrinsic (due to the own embryo) and extrinsic (laboratorial procedures) mechanisms may be involved. Developmental competence after IVM and IVF is lower for prepubertal lamb oocytes than it is for adult ewe oocytes (Ledda et al., 1999). The lack of an effect of the organic feed alone in experiment 1 might have been because of the age of the ewe lambs, which were 15 days older than were the ewes in experiment 2 . Hormonal stimulation and lamb age increased the production of embryos from prepubertal lambs. In addition, the response to stimulation did not affect embryo production from 3-4-week-old lambs, although by 6-7 weeks of age a high response to stimulation reduced blastocyst formation (Morton et al., 2005).

The results from the organic-fed and the conventional-fed ewes in experiment 1 , and by the conventional-fed ewes in experiment 2, were similar to the results from similar-aged ewe lambs of the same breed in our previous studies (Abecia et al., 2014, 2015). Our studies did not include an induced "polluted-fed" group because the control group was fed a conventional diet that was not artificially contaminated and, presumably, met sheep requirements. Therefore, it seems that the ovaries from organic-bred ewe lambs can be a better source of oocytes for IV procedures. It is still to be determined why these oocytes did not achieve a higher blastocyst yield.

\section{Conclusion}

The results of our preliminary study indicated that the total integration of the animals in a fully organic system improved oocyte quality in ewe lambs. Future experiments, 
including a higher number of animals from different organic and conventional farms, a chemical analysis of the feed ingredients, measurement of stress, and standardizing the age of the animals are necessary.

\section{Acknowledgements}

We thank the organic farmer for his collaboration, and Bruce MacWhirter (Fortaleza Edicion) for suggestions on the English version of the manuscript. The research was partially supported by the Gobierno de Aragón (A26) and project AGL2012-37219 from MICINN (Spain).

\section{Statement of Interest}

None

\section{Ethical Standards}

The authors assert that all procedures contributing to this work comply with the ethical standards of the relevant national (Spanish Policy for Animal Protection RD1201/05) and institutional (Ethic Committee for Animal Experiments from the University of Zaragoza) guides on the care and use of laboratory animals, which meets the European Union Directive 2010/63/EU on the protection of animals used for experimental and other scientific purposes.

\section{References}

Abecia, J.A., Casao, A., Pascual-Alonso, M., Lobón, S., Aguayo-Ulloa, L.A., Forcada, F., Meikle, A.: Sosa, C., Marín, R.H., Silva, M.A., Maria, G.A. (2015). Periconceptional undernutrition increases quantity and quality of oocyte population, but not cognitive or emotional response of 60-day-old lambs J. Anim. Physiol. Anim. Nutr. 99, 501-10.

Abecia, J.A., Casao, A., Pascual-Alonso, M., Lobón, S., Aguayo-Ulloa, L.A., Meikle, A., Forcada, F., Sosa, C., Marín, R.H., Silva, M.A., Maria, G.A. (2014). The effect of periconceptional undernutrition of sheep on the cognitive/emotional response and oocyte quality of offspring at 30 days of age. J. Dev. Orig. Health Dis. 5, 79-87.

AFRC (1993). Energy and Protein Requirements of Ruminants. An Advisor Manual Prepared by the Agricultural and Food Research Council Technical Committee on Responses to Nutrients. CAB International,Wallingford, UK.

Alrøe, H.F., Vaarst, M., Kristensen, E.S. (2001). Does organic farming face distinctive 
livestock welfare issues? - A conceptual analysis. J. Agr .Environ. Ethic. 14, 275-99. Ashworth, C.J., Toma, L.M., Hunter, M.G. (2009). Nutritional effects on oocyte and embryo development in mammals: implications for reproductive efficiency and environmental sustainability. Phil. Trans. R. Soc. B 364, 3351-61.

Bellingham, M., Amezaga, M.R., Mandon-Pepin, B., Speers, C.J., Kyle, C.., Evans, N.P., Sharpe, R.M., Cotinot, C., Rhind, S.M., Fowler, P.A. (2013). Exposure to chemical cocktails before or after conception - The effect of timing on ovarian development. Mol. Cell Endocrinol. 376,156-72.

Bloomfield, F.H. (2011). Epigenetic modifications may play a role in the developmental consequences of early life events. J. Neurodev. Disord. 3, 348-55.

European Commission (2007). Council Regulation (EC) No 834/2007 of 28 June 2007 on organic production and labelling of organic products and repealing Regulation (EEC) No 2092/91. Available in http://eurlex.europa.eu/LexUriServ/LexUriServ.do?uri=OJ:L:2007:189:0001:0023:EN:PDF

Forcada, F., Buffoni, A., Abecia, J.A., Asenjo, B., Palacín, I., Vázquez M.I., RodríguezCastillo, J.D.C., Sánchez-Prieto, L., Casao, A. (2011). Maximising embryo production in endangered sheep breeds: in vitro procedures that complement in vivo techniques. J. Appl. Anim. Res. 39, 412-17.

Fowler, P.A., Dora, N.J., McFerran, H., Amezaga, M.R., Miller, D.W., Lea, R.G., Cash, P., McNeilly, A.S., Evans, N.P., Cotinot, C., Sharpe, R.M., Rhind, S.M. (2008). In utero exposure to low doses of environmental pollutants disrupts fetal ovarian development in sheep. Mol. Hum. Reprod.14, 269-80.

Hou, Y.J., Xiong, B., Zheng, W.J., Duan, X., Cui, X.S., Kim, N.H., Wang, Q., Xu, Y.X., Sun, S.C. (2014). Oocyte quality in mice is affected by a mycotoxin-contaminated diet. Environ. Mol. Mutagen. 55, 354-62.

Lea, R.G., Amezaga, M.R., Loup, B., Mandon-Pépin, B., Stefansdottir, A., Filis, P., Kyle, C., Zhang, Z., Allen, C., Purdie, L., Jouneau, L., Cotinot, C., Rhind, S.M., Sinclair, K.D., Fowler, P.A.. (2016).The fetal ovary exhibits temporal sensitivity to a 'real-life' mixture of environmental chemicals Sci. Rep. 6, 22279.

Ledda, S., Bogliolo, L., Leoni, G., Naitana, S. (1999). Production and lambing rate of blastocysts derived from in vitro matured oocytes after gonadotropin treatment of prepubertal ewes. J. Anim. Sci. 77, 2234-39.

Lepherd, M., Canfield, P., Hunt, G., Thomson, P., Bosward, K. (2011). Assessment of the Short-term systematic effect of and acute phase response to mulesing and other 
options for controlling breech flystrike in Merino lambs. Aust. Vet. J. 89, 19-26.

Morton, K.M., Catt, S.L., Maxwell, W.M., Evans, G. (2005). Effects of lamb age, hormone stimulation and response to hormone stimulation on the yield and in vitro developmental competence of prepubertal lamb oocytes. Reprod. Fertil. Dev. 17, 593-601.

Rhind, S.M., Rae, M.T., Brooks, A.N. (2001). Effects of nutrition and environmental factors on the fetal programming of the reproductive axis. Reproduction 122, 205-14.

Smith, J., Ferguson, D., Jauregui, G., Panarce, M., Medina, M., Lehnert, S., Hill, J.R. (2008). Short-term maternal psychological stress in the post-conception period in ewes affects fetal growth and gestation length. Reproduction 136, 259-65.

Wani, N.A., Wani, G.M., Khan, M.Z., Sidiqi, M.A. (1999). Effect of different factors on the recovery rate of oocytes for in vitro maturation and in vitro fertilization procedures in sheep. Small Rumin. Res. 34, 71-6. 
Table 1 Number (mean \pm SEM) and percentage of good, fair, poor, and healthy oocytes, and the results of the in vitro maturation (IVM) and fertilization (IVF) procedures per ewe lamb, recovered from the ovaries of 2-month-old ewe lambs born from ewes fed either organic feed $(n=6)$ or conventional feed $(n=6)$ from 15 days before mating until weaning.

\begin{tabular}{llll} 
& Organic & Conventional & P-value \\
\hline Good (\%) & $8.3 \pm 2.9(25.8 \%)$ & $10.0 \pm 3.2(27.2 \%)$ & $>0.05$ \\
Fair (\%) & $3.8 \pm 0.8(11.8 \%)$ & $3.6 \pm 1.0(9.9 \%)$ & $>0.05$ \\
Poor (\%) & $20.2 \pm 9.6(62.4 \%)$ & $23.2 \pm 9.2(63.0 \%)$ & $>0.05$ \\
Total & $32.3 \pm 11.8$ & $36.8 \pm 13.1$ & $>0.05$ \\
Healthy & & & \\
(good + fair) (\%) & $12.2 \pm 3.3(37.6 \%)$ & $13.6 \pm 4.0(37.0 \%)$ & $>0.05$ \\
\hline IVM & $60 / 75(80.0 \%)$ & $46 / 64(71.9 \%)$ & $>0.05$ \\
IVF & $60 / 60(100.0 \%)$ & $45 / 46(97.8 \%)$ & $>0.05$ \\
Cleavage rate 48 h & $55 / 75(73.3 \%)$ & $43 / 64(67.2 \%)$ & $>0.05$ \\
Blastocysts rate & & & $>0.05$ \\
(blastocyst/embryos) & $0 / 55(0.0 \%)$ & $3 / 43(7.5 \%)$ & \\
Blastocysts rate & & & $>0.05$ \\
(blastocyst/oocyte) & $0 / 75(0.0 \%)$ & $3 / 64(4.7 \%)$ & \\
\hline
\end{tabular}


Table 2 Number (mean \pm SEM) of good, fair, and poor oocytes, and the results of the in vitro maturation (IVM) and fertilization (IVF) procedures per ewe lamb, recovered from ovaries of 45 -day-old ewe lambs born on an organic $(n=6)$ or a conventional $(n=6)$ sheep farm.

\begin{tabular}{llll} 
& Organic & Conventional & P-value \\
\hline Good (\%) & $27.4 \pm 3.6(38.3 \%)$ & $18.0 \pm 3.8(28.6 \%)$ & $>0.05$ \\
Fair (\%) & $12.2 \pm 1.7(17.0 \%)$ & $7.0 \pm 1.8(11.1 \%)$ & $<0.05$ \\
Poor (\%) & $32.0 \pm 6.8(44.7 \%)$ & $38.0 \pm 6.4(60.3 \%)$ & $>0.05$ \\
Total & $71.6 \pm 10.8$ & $63.0 \pm 7.6$ & $>0.05$ \\
Healthy & & & \\
(good + fair) (\%) & $39.6 \pm 5.2(55.3 \%)$ & $25.0 \pm 4.2(39.7 \%)$ & $<0.0001$ \\
\hline IVM & $150 / 196(76.5 \%)$ & $78 / 147(53.1 \%)$ & $<0.0001$ \\
IVF & $146 / 150(97.3 \%)$ & $71 / 78(91.0 \%)$ & $<0.05$ \\
Cleavage rate 48 h & $120 / 196(61.2 \%)$ & $68 / 147(46.3 \%)$ & $<0.01$ \\
Blastocysts rate & & & $<0.05$ \\
(blastocyst/embryos) & $2 / 120(1.7 \%)$ & $6 / 68(8.8 \%)$ & $>0.05$ \\
Blastocysts rate & & & \\
(blastocyst/oocyte) & $2 / 196(1.0 \%)$ & $6 / 147(4.1 \%)$ & \\
\hline
\end{tabular}

